\title{
WILSON PLOT METHOD TO OBTAIN NUSSELT NUMBER FOR A PLATE HEAT EXCHANGER
}

\author{
D. dos S. Ferreira ${ }^{a}$, \\ M. Mantellia, \\ and F. Milanese ${ }^{b}$ \\ ${ }^{\text {a }}$ Universidade Federal de Santa Catarina \\ Departamento de Engenharia Mecânica \\ Rua Lauro Linhares, 1850, Trindade, 88070260 \\ Florianópolis, Santa Catarina, Brasil \\ ferreira.dijane@labtucal.ufsc.br \\ ${ }^{\mathrm{b}}$ Universidade Federal de Santa Catarina \\ Centro de Ciência, Tecnologia e Saúde \\ Rua Gov. Jorge Lacerda, 3201, Urussanguinha, \\ Araranguá, Santa Catarina, Brasil. \\ milanez@labtucal.ufsc.br \\ Received: Dec 07, 2020 \\ Revised: Dec 17, 2020 \\ Accepted: Dec 18, 2020
}

\begin{abstract}
Plate heat exchangers are devices commonly used in industry due to their high efficiency and ease cleaning. Although its first use was in food sector, nowadays this equipment can be found in most industrial segments, like chemistry and oil industry. Due the facility of fabrication, the corrugated gasket plate heat exchanger is amply utilized in those segments, however, its mathematical analysis present non-agreement between the authors, because of the different plate models and operation settings. Thus, the main objective of this work is to study the application of the Wilson-Plot method to analyze the thermal behavior of an elemental plate heat exchanger, and verify if the operation temperature has significant influence in the thermal behavior of the plate heat exchanger.
\end{abstract}

Keywords: plate exchanger; corrugated plate; wilson plot; Nusselt number

\section{NOMENCLATURE}

a corrugation depth, $\mathrm{m}$

$\mathrm{C}_{2}$ constant

$\mathrm{d}_{\mathrm{h}} \quad$ hydraulic diameter, $\mathrm{m}$

f viscous friction factors

F correction factor for the cross flow arrangement

G fluid mass velocity

h local convection coefficient

$\mathrm{L}_{\mathrm{p}} \quad$ plate vertical length, $\mathrm{m}$

$\dot{\mathrm{m}}$ mass flow rate, $\mathrm{kg} / \mathrm{s}$

$\mathrm{Nu}$ Nusselt number

Pr Prandtl number

$Q_{\text {ave }}$ average heat transfer rate

$\mathrm{R}_{\text {wall }}$ thermal resistance from the wall, ${ }^{\circ} \mathrm{Cm}^{2} / \mathrm{W}$

Re Reynolds number

$\mathrm{T}$ fluid temperature, $\mathrm{K}$

$\mathrm{U}$ global heat exchanger coefficient, $\mathrm{W} /{ }^{\circ} \mathrm{Cm}^{2}$

$\mathrm{W}_{\mathrm{p}} \quad$ plate horizontal length, $\mathrm{m}$

\section{Greek symbols}

$\begin{array}{ll}\tau & \text { dimensionless time } \\ \beta & \text { plate chevron angle } \\ \kappa & \text { thermal conductivity } \\ \lambda & \text { corrugation pitch } \\ \xi & \text { viscous friction factors } \\ \mu & \text { fluid viscosity } \\ \pi & \text { pi }\end{array}$

$\varphi \quad$ plate enlargement factor

$\psi \quad$ constant

$\begin{array}{ll}\text { Subscripts } \\ \text { ave } & \text { average } \\ \text { b } & \text { bulk } \\ \text { C } & \text { constant } \\ \text { h } & \text { hydraulic } \\ \text { H } & \text { hot } \\ \text { ml } & \text { mean log } \\ \text { p } & \text { plate } \\ \text { w } & \text { wall }\end{array}$

\section{Superscripts}

$\begin{array}{ll}\text { n } & \text { constant } \\ \text { c } & \text { constant }\end{array}$

\section{INTRODUCTION}

Plate heat exchangers are devices commonly used in industry. This first application (1866) was in liquid-liquid configuration, for the pasteurization of the milk in dairy sector, as an outcome of the tuberculosis outbreak, associated to the raw milk ${ }^{1}$. Nowadays, these heat exchangers are employed in the major industries, including oil and chemistry, due to their high compactness, high heat transfer capacity and low pressure drop, if compared with more 
conventional technologies, such as the shell and tube units ${ }^{2}$.

Since their creation, to the current days, the plate geometries for those exchangers have changed a lot. Among several models, the chevron plate (or herringbone), showed in the Figure 1, is the most common ${ }^{1}$. Moreover, the gasket plates are the most common model of plate heat exchangers, which, however, present tight limitations for operations under high temperature and pressure conditions.

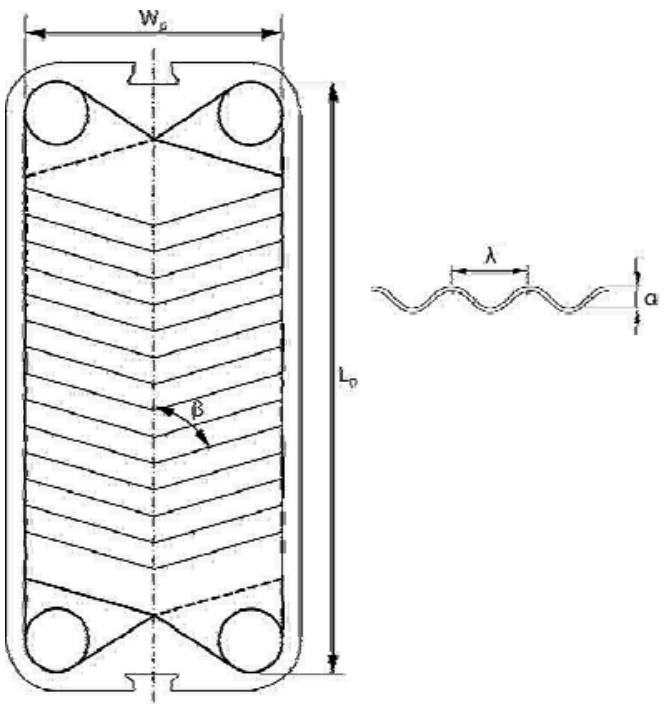

Figure 1. Schematic drawing of corrugated plate heat exchanger's plate.

Figure 1 shows a schematics of a corrugated plate, where $\mathrm{W}_{p}$ is the width effective of the horizontal plate and $\mathrm{L}_{p}$ is the vertical length (both dimensions include the nozzles), $\lambda$ is the corrugation pitch, $\beta$ is the chevron angle and $\mathrm{a}$ is the corrugation depth.

Many researchers discuss about the best correlations for predicting the heat transfer in gasket plate heat exchangers (GPHE). Based on experimental results, correlations are proposed in which the input parameters are: the plate geometry, such as the chevron angle $(\beta)$, and the operating conditions, such as the mass velocity $(\mathrm{G})$ and mass flow rate $(\dot{m})$. Actually these last parameters determine the Reynolds number.

One of the techniques utilized to evaluate the heat transfer in GPHE is the Wilson-Plot method, which, considers that the global heat transfer of the heat exchanger is a function of its global thermal resistance ${ }^{3,5}$. Moreover, in this technique, the global resistance is a function of the local thermal resistance of each fluid and of the plate walls. The experimental procedure proposed in this method considers that, one of the fluids flows at constant velocity, so that its local thermal resistance remains constant, while the second fluid flows at variable velocity, and, consequently, its local thermal resistance is also variable.
In this way, the main objective of this paper is to use the Wilson-Plot method to evaluate the thermal behavior of a GPHE, and to verify if the range of temperatures studied has influence in the Nusselt number.

\section{THEORETICAL ANALYSIS}

The thermal behavior of GPHEs are closely affected by the following geometrical parameters of the plates: corrugation pitch $(\lambda)$ and depth $(a)$, chevron angle $(\beta)$ and plate horizontal $\left(\mathrm{W}_{\mathrm{p}}\right)$ and vertical $\left(L_{p}\right)$ lengths. Another important parameter, used for many researchers such as Kapustenko et al. (2011), Kim and Park (2017) and Martin (1996), is the ratio between the developed and the projected areas is the plate enlargement factor $(\varphi)$, understood a function of the corrugation pitch and depth, being given by:

$$
\varphi(X)=\frac{1}{6}\left(1+\sqrt{1+X^{2}}+\sqrt{1+\frac{X^{2}}{2}}\right)
$$

where $\mathrm{X}$ is:

$$
\mathrm{X}=\frac{\pi \mathrm{a}}{\lambda}
$$

Some authors as Khan et al. 2010; Kim and Park 2017; Martin 1996 used the hydraulic diameter concept to analyze the thermal behavior of GPHE, this variable is given by:

$$
\mathrm{d}_{\mathrm{h}}=\frac{2 \mathrm{a}}{\varphi}
$$

where $a$ is the corrugation depth and $\varphi$ the enlargement factor of the plate. The fluid mass velocity is also obtained as function of the geometric parameters of the plate, i.e.:

$$
\mathrm{G}=\frac{\dot{\mathrm{m}}}{\mathrm{aW} \mathrm{P}_{\mathrm{P}} \mathrm{N}_{\mathrm{P}}}
$$

where $\mathrm{N}_{p}$ is the number of flow passages in the GPHE. In addition, the Reynolds number is determined as a function of the mass velocity and the hydraulic diameter, be the expression:

$$
\mathrm{Re}=\frac{\mathrm{Gd}_{\mathrm{h}}}{\mu}
$$

In this work, the thermal performance of a GPHE operating in a cross flow arrangement (see Figure 2) is determined using the Wilson-Plot Method. For this 
purpose, the global heat exchanger coefficient must be determined using the expression:

$$
\mathrm{U}=\frac{\mathrm{Q}_{\mathrm{ave}}}{\mathrm{FA} \Delta \mathrm{T}_{\mathrm{ml}}}
$$

where $\mathrm{Q}_{\text {ave }}$ is the average heat transfer rate, $A$ is the area of the exchanger, $\Delta \mathrm{T}_{\mathrm{ml}}$ is the mean $\log$ temperature difference and $F$ is the correction factor for the cross flow arrangement.

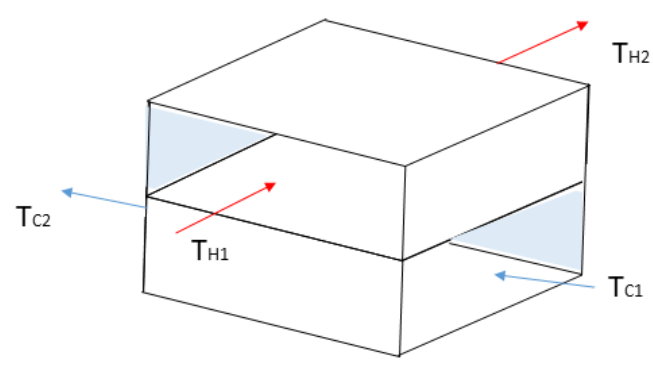

Figure 2. Cross flow GPHE. Adapted from: Baehr e Stephan (1998).

The global heat exchanger coefficient is also a function of the thermal resistances of the hot and cold flows and of the wall:

$$
\frac{1}{\mathrm{U}}=\frac{1}{\mathrm{~h}_{\mathrm{H}}}+\mathrm{R}_{\mathrm{w}}+\frac{1}{\mathrm{~h}_{\mathrm{C}}}
$$

where $\mathrm{h}_{H}$ and $\mathrm{h}_{C}$ are the local convection coefficients of the hot and cold fluid flows, respectively, and $\mathrm{R}_{\text {wall }}$ is the thermal resistance from the wall $\left({ }^{\circ} \mathrm{C} \mathrm{m}{ }^{2} / \mathrm{W}\right)$.

To use the Wilson-Plot method, the hot fluid of GPHE is considered as operating at different velocities ( $h_{H}$ variable) while the cold fluid remains constant ( $h_{C}$ constant). Therefore, as shown in Figure 2 , the overall heat exchanger coefficient depends only of the hot fluid velocity. This curve can be approximated by the following expression:

$$
\frac{1}{\mathrm{U}}=\frac{\mathrm{V}_{\mathrm{H}}^{-\mathrm{n}}}{\mathrm{C}_{2}}+\left(\mathrm{R}_{\text {wall }}+\frac{1}{\mathrm{~h}_{\mathrm{C}}}\right)
$$

where $\mathrm{v}_{H}$ are the hot fluid velocity and $n$ and $\mathrm{C}_{2}$ are constants. The values of the constants are obtained through extrapolation of the plot of $1 / \mathrm{U}$ as a function of $\mathrm{V}^{-\mathrm{n}}$, as shown in Figure 3, where the inclination angle represents $\mathrm{C}_{2}$ and the interception point represents the constant portion of the global thermal resistance, composed by the wall and the cold fluid resistances. Therefore, the local thermal convective coefficient for the hot fluid is a function of the velocity flow and given by:

$$
\mathrm{h}_{\mathrm{H}}=\mathrm{h}(\mathrm{v})=\mathrm{C}_{2} \mathrm{v}_{\mathrm{H}}^{\mathrm{n}}
$$

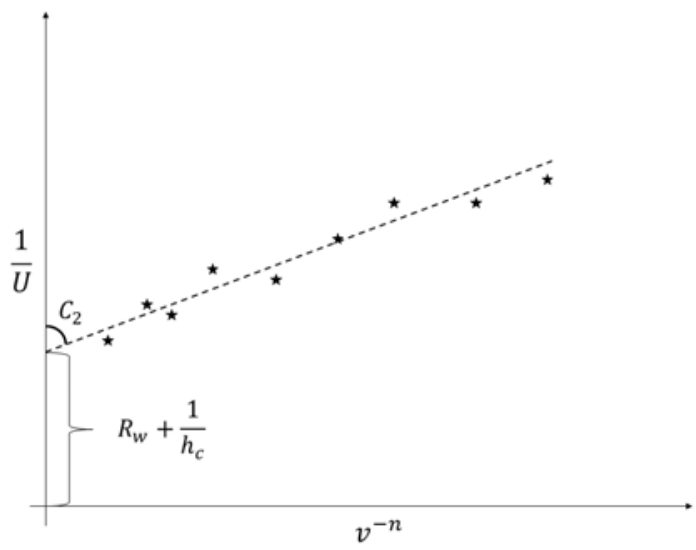

Figure 3. Wilson Plot method graph.

Commonly in thermal science, the heat transfer coefficient is given in terms of the Nusselt number $(\mathrm{Nu})$, which is a non-dimensional parameter obtained from the local thermal convection coefficient, given by:

$$
\mathrm{Nu}=\frac{\mathrm{hd}}{\kappa}
$$

where $\mathrm{d}_{h}$ is the hydraulic diameter and $\kappa$ is the thermal conductivity.

As already pointed out in the introduction section, since its creation, the thermal behavior of GPHE has been the subject of several studies; however, the resulting correlations do not show good agreement among themselves. Actually, many correlations, used for different fields, application conditions and plate geometries are available.

From these correlations, the two presented in Eqs. (11) and (12) are based on data obtained from test conditions similar to the ones of the present work and so they are used in order to get theoretical predictions that are used in the comparison with experimental results, so as to validate the technique previously described.

Firstly, Shah and Sekulic 2003 presented a correlation for Nusselt number as a function of the Fanning friction factor, with applications for $0<\beta<80^{\circ}$ and $0<\operatorname{Re} \geq 2000$, given by:

$$
\mathrm{Nu}=0.205 \operatorname{Pr}^{\frac{1}{3}}\left(\frac{\mu_{\mathrm{b}}}{\mu_{\mathrm{w}}}\right)^{\frac{1}{6}}\left[\mathrm{fRe}^{2} \sin (2 \beta)\right]^{0.374}
$$

Kapustenko et. al. (2011) presented a correlation for Nusselt number as function of the Moody friction factor, with applications for $14^{\circ}<\beta<85^{\circ}$, $100<\operatorname{Re}<25000$ and $1.14<\varphi<1.5$, given by: 


$$
\mathrm{Nu}=0.065 \operatorname{Re}^{\frac{6}{7}}\left(\frac{\xi \psi}{\varphi}\right)^{\frac{3}{7}} \operatorname{Pr}^{c}\left(\frac{\mu_{\mathrm{b}}}{\mu_{\mathrm{w}}}\right)^{0.14}
$$

In Eqs. (11) and (12), $\mu_{\mathrm{b}}$ and $\mu_{\mathrm{w}}$ are the viscosities at the bulk and the wall temperatures, respectively, $f$ and $\xi$ are the viscous friction factors, $\mathrm{Re}$ is the Reynolds number, Pr is the Prandtl number, $\varphi$ is the enlargement factor of the plate, $\beta$ is the chevron angle of the plate, and $\psi$ and $c$ are constants. More information about these correlations can be found in Rose 2004).

\section{PROCEDURES}

The experimental data used to compare with the model predictions were obtained from measurements performed in a set of welded plates that represents to core of the GPHE. As show in Fig. 4, the elemental core was assisted by nozzles. Water as used the working fluid for both hot and cold streams.

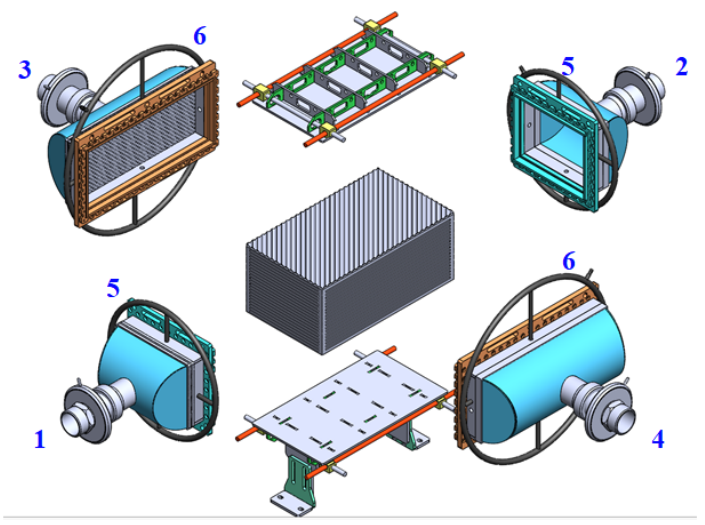

Figure 4. Elemental GHPE

The points 1 and 3 are the entrances of the hot and cold fluid streams, while points 3 and 4 are the outputs, respectively. The rings 5 and 6 represents the pressure sockets.

All the tests were made for the hot water temperatures varying between 40 and $60^{\circ}$, for different Reynolds numbers. In those tests, the cold water remains at a constant mass flow (constant Reynolds). The configurations of the tests performed are found in the Table 1, where, for each mass flow value, the hot stream inlet temperature ranged from 40 to $60^{\circ} \mathrm{C}$, with $5^{\circ} \mathrm{C}$ of temperature increment. All the data were obtained in steady-state conditions. The geometric parameters of the plates used in the tests were chevron angle $(\beta)$ of $32.5^{\circ}$, corrugation depth (a) of $0.004 \mathrm{~m}$, corrugation pitch $(\lambda)$ of 0.01 and the lengths $\mathrm{W}_{p}$ and $\mathrm{L}_{p}$ are the same, equal to $0.210 \mathrm{~m}$.

Table 1. Test condition

Hot fluid, Cold fluid, mass Hot fluid, inlet

\begin{tabular}{ccc}
\hline $\begin{array}{c}\text { mass flow } \\
{[\mathrm{kg} / \mathrm{s}]}\end{array}$ & flow $[\mathrm{kg} / \mathrm{s}]$ & temperature $\left[{ }^{\circ} \mathrm{C}\right]$ \\
\hline 1.35 & & \\
1.45 & & \\
1.56 & 1.12 & $40-60^{\circ} \mathrm{C}$ \\
1.71 & & \\
1.86 & & \\
2.00 & & \\
\hline
\end{tabular}

For each one of the mass flow in the Table 2 ranged the hot inlet temperature for 40 to $60^{\circ} \mathrm{C}$ with a $5^{\circ} \mathrm{C}$ of temperature increment. All the data were obtained in steady-state.

\section{RESULTS}

The analysis of the data was made with the help of Excel and EES software. The Nusselt number for the GHPE was determined following the method described previously. No error bars are shown in the graphs (Figures 5 to 12), because the experimental uncertainty did not present significant results (less than $1 \%$ ) and cannot be represented graphically.

Figure 5 shows the global coefficient of heat transfer (Eq. 5) as a function of the Reynolds Number (Eq. 4) for different temperatures. These results show that, for the range tested, the temperature level does not play an important role on the Global coefficient of heat transfer. Besides, it is possible to see in the graph, that the Reynolds number affects significantly the global heat transfer coefficient, as expected.

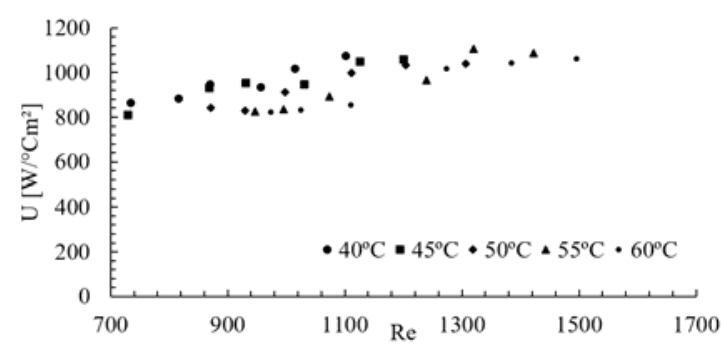

Figure 5. Global heat transfer coefficient

Figures 6 and 7 show the Wilson-Plot method applied to the experimental data. It is possible to see that the behavior of the graphs (inclination curves) have the same form in both graphs. The value for the constant $C_{2}$ in the graphs of Figures 6 and 7 are the same, equal to $4 \cdot 10^{-5}$. With the Wilson Plot method results, it was possible to obtain the Nusselt number values, using the equations 8 and 9 . 


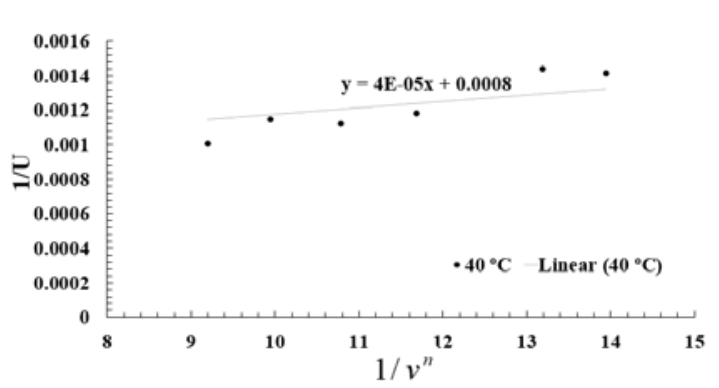

Figure 6. Wilson Plot Method, $40^{\circ} \mathrm{C}$

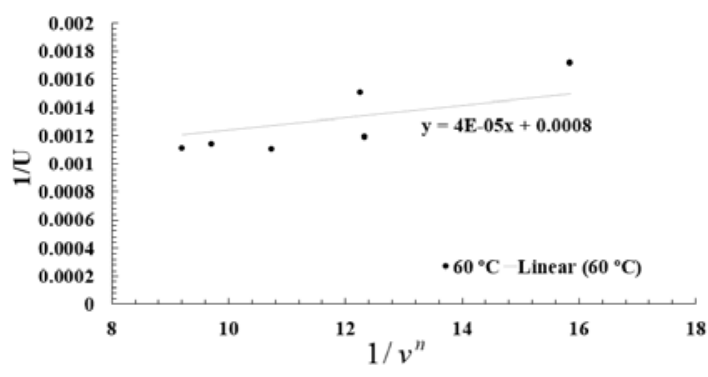

Figure 7. Wilson Plot Method, $60^{\circ} \mathrm{C}$

Figure 8 shows the behavior of the Nusselt number with the Reynolds number. As expected, the increase of the Reynolds number due to the increase of velocity results in an increase of the Nusselt number, once larger velocities result in higher heat transfer coefficients. In addition, it is possible to see that the temperature (in the tested range) has no major influence over the Nusselt number behavior. On the other hand, the points are transferred in the horizontal axis for the different temperatures, this effect can be explained by the temperature influence in the Reynolds number, expressed in terms of the fluid viscosity (see equation 4) which is inversely proportional to the temperature, it is possible to see this behavior in Fig. 9. The Reynolds number points are aligned for the different temperatures, but its vertical increase is justified by the fluid viscosity decrease.

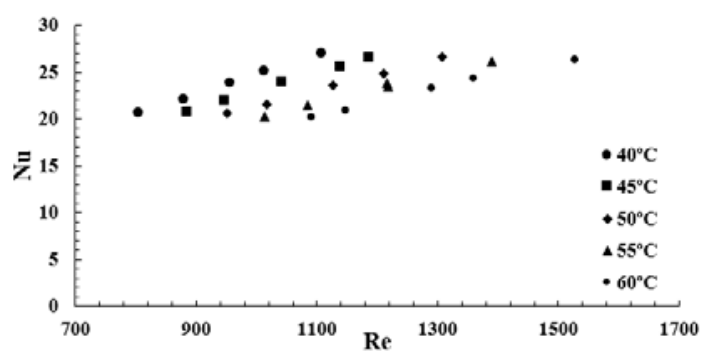

Figure 8 . Nusselt number in function of Reynolds number

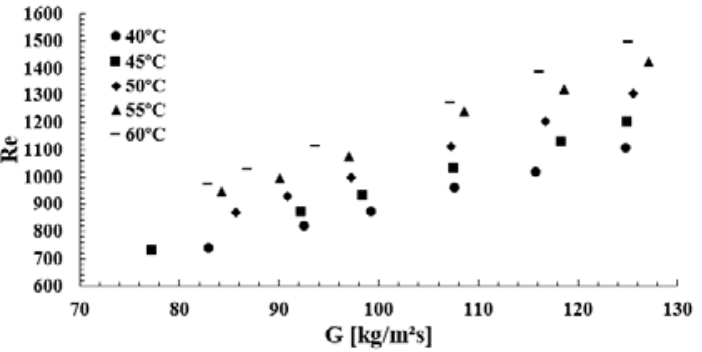

Figure 8. Reynolds number in function of mass velocity

Figures 10 to 12 show the comparison between the experimental data, obtained by the Wilson Plot method, and the literature correlations. The difference between the experimental data and the correlations is less than $15 \%$, for both correlations previously selected (Kapustenkoet al. (2011) and Shah and Sekulic (2003). This shows, actually, a good agreement, as, according to the authors, the data lay within the error range of the correlation. These results also validate the Wilson Plot as a method for predicting the Nusselt number in plate heat exchangers.

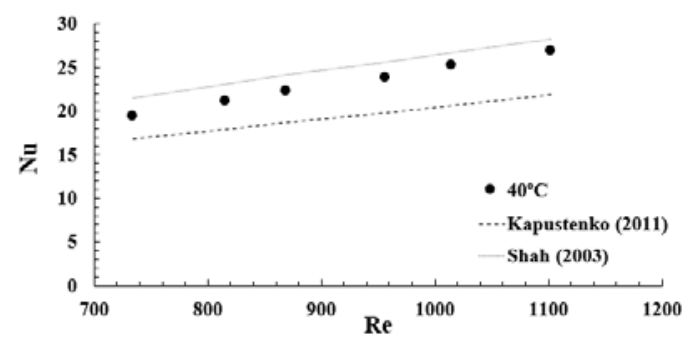

Figure 9. Comparison between the experimental data and the literature correlations for Nusselt number. For $40^{\circ} \mathrm{C}$

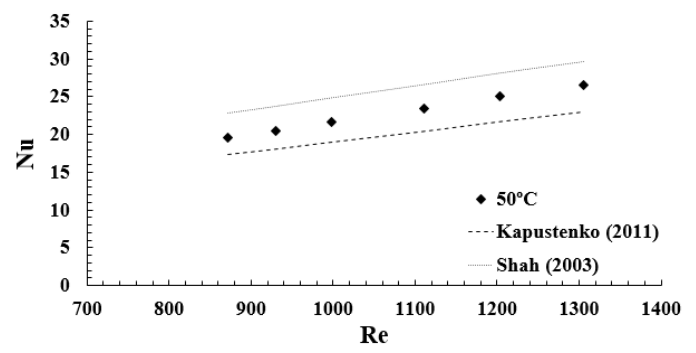

Figure 10. Comparison between the experimental data and the literature correlations for Nusselt number. For $50^{\circ} \mathrm{C}$ 


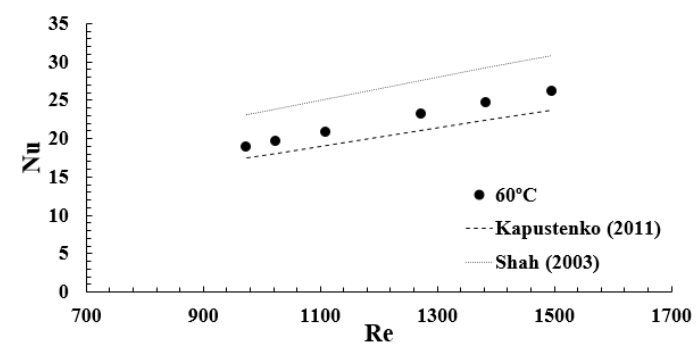

Figure 11. Comparison between the experimental data and the literature correlations for Nusselt number. For $60^{\circ} \mathrm{C}$

The results for the other temperature values were not showed here because they present not significantly variation of Nusselt number.

\section{CONCLUSIONS}

The results show that, for GPHE, the Nusselt numbers can be obtained from Wilson-Plot method. The analysis was made varying the inlet hot fluid temperature and the mass flow, while maintaining the mass flow constant, for the cold fluid.

It is possible to observe an increase of the Nusselt number as a consequence of the increase of the Reynolds number, as these parameters are directly correlated. Besides that, the Reynolds number increase with the flow velocity increase. Also, with the temperature increase, the fluid viscosity behavior changes and the coefficient of heat transfer increase, increasing the Nusselt number.

In addition, it was possible to discover that, for the range tested, the temperature has no major influence over the Nusselt number behavior. This can be explained because the water presents no significantly changes of the thermodynamic properties, for the temperature range tested.

In conclusion, it is possible to see that the Wilson Plot method is a high effective technique to analyze the thermal behavior in a GPHE, once the experimental data presents a good concordance with the literature correlations (less than 15\%), within the uncertainty range of the correlations.

\section{REFERENCES}

Wang, L., Sundén, B. \& Manglik, R. M. Plate Heat Exchangers: Design, Applications and Performance. (Wit Press, 2007).

Hajabdollahi, H., Naderi, M. \& Adimi, S. A comparative study on the shell and tube and gasketplate heat exchangers: The economic viewpoint. Appl. Therm. Eng. (2016). doi:10.1016/j.applthermaleng.2015.08.110

Kim, M. B. \& Park, C. Y. An experimental study on single phase convection heat transfer and pressure drop in two brazed plate heat exchangers with different chevron shapes and hydraulic diameters. J. Mech. Sci. Technol. 31, 2559-2571 (2017).

Martin, H. A theoretical approach to predict the performance of chevron-type plate heat exchangers. Chem. Eng. Process. Process Intensif. (1996). doi:10.1016/0255-2701(95)04129-X

Rose, J. W. Heat-transfer coefficients, Wilson plots and accuracy of thermal measurements. Exp. Therm. Fluid Sci. (2004). doi:10.1016/S08941777(03)00025-6

Kapustenko, P., Arsenyeva, O. \& Dolgonosova, $\mathrm{O}$. The heat and momentum transfers relation in channels of plate heat exchangers. Chem. Eng. Trans. 25, 357-362 (2011).

Khan, T. S., Khan, M. S., Chyu, M. C. \& Ayub, Z. H. Experimental investigation of single phase convective heat transfer coefficient in a corrugated plate heat exchanger for multiple plate configurations. Appl. Therm. Eng. (2010). doi:10.1016/j.applthermaleng.2010.01.021 